\title{
Understanding Interaction of Curcumin and Metal Ions on Electrode Surfaces Using EDXRF
}

\author{
Daisy Joseph ${ }^{1 *}$, Krishna Kumar ${ }^{2}$ and S Narayan ${ }^{2}$ \\ ${ }^{1}$ Nuclear Physics Division, BARC, Trombay, Mumbai, India \\ ${ }^{2}$ Department of Chemistry, University of Madras, India \\ *Corresponding Author: Daisy Joseph, Nuclear Physics Division, BARC, Trombay, \\ Mumbai, India.
}

Received: November 06, 2021

Published: December 31, 2021

(C) All rights are reserved by Daisy Joseph., et al.

\begin{abstract}
A chemically modified electrode was developed for determination of metal ions ( $\mathrm{Cd}, \mathrm{Pb}, \mathrm{Zn}, \mathrm{Co}, \mathrm{Hg}$ ). The modifier used for the study was Curcumin. Curcumin acts as a complexing agent at the surface of the electrode for preconcentration of metal ions from electrolyte to electrode surface and stripped back to electrolyte during analysis. EDXRF was use to analyze these electrodes and it was concluded that the PCR modified electrode favored effective chelation for lead and mercury.
\end{abstract}

Keywords: Mercury; Curcumin; EDXRF

\section{Introduction}

In this study, a chemical analysis of ligand (curcumin) and its metal complexes at the surface electrode were analyzed using ED-XRF. A novel mercury free ligand based electrode was developed for determination of metal ions present in the sea water. The electrode surface was modified with Curcumin, a natural chelating agent via electropolymerization technique [1]. The surface of the bare electrode was coated with polycurcumin film and applied for preconcentration of metal ions. In order to understand the changes occurred to curcumin at the electrode surface during electropolymerization and metal ion preconcentration [2]. EDXRF was carried. Basically 3 steps were involved during the analysis process, Pre-concentration, Reduction of metal ion, differential pulse stripping analysis. We want to understand the state of metal ions at the electrode surface and the interaction between curcumin and metal ion during the analysis. Since curcumin is fluorescent we could not record Raman spectra, Hence XPS or EDXRF studies had to be carried out. This is the first attempt to carry out EDXRF analysis of curcumin-metal complex at solid surface. We have recorded solid state DRS UV and AT-IR using this samples in order to study the curcumin-metal complex at electrode surface.

\section{Experimental Methods}

Material is Paraffin wax impregnated graphite electrode. Elements present in the surface of the electrode is $\mathrm{C}, \mathrm{O}, \mathrm{N}$ for Curcumin and metal ions (Cd, $\mathrm{Zn}, \mathrm{Pb}, \mathrm{Co}, \mathrm{Hg}$ ). The sample (Graphite rod) was purchased from sigma-aldrich the rod is pretreated with paraffin wax under vacuum and the surface is polished in abrasive sheet. Curcmin is drop casted over the smooth surface of graphite rod and connected to the electrochemical work station as a working electrode. Metal ions such as $\mathrm{Cd}, \mathrm{Pb}, \mathrm{Zn}$ etc. present in the aqueous electrolytes get electrochemically deposited over the curcumin modified graphite rod under respective reduction potential for each metal ion. For EDXRF measurements a Jordan Valley EDXRF spectrometer (EX-3600 TEC) with a Rh target low power X-ray tube was used. The spectrometer is equipped with a ten position sample chamber. For the detection of X-rays, a peltier cooled Si-PIN Diode detector with a resolution of $150 \mathrm{eV}$ at $5.9 \mathrm{keV}(\mathrm{Mn} \mathrm{K \alpha})$ was used. For background reduction in the spectra $\mathrm{Rh}$ radiation filter filter was used. The applied voltage and current were $40 \mathrm{kV}, 1000 \mu \mathrm{A}$, respectively. The samples were taken in a 12 micron thick mylar window sample holder and for the measurement of EDXRF spectra. 
The measurement time was 100s. Different electrode such as bare electrode, polycurcumin (PCR) film electrode, PCR-Pb preconcentrated electrode, PCR-Zn preconcentrated electrode, PCR-Hg preconcentrated electrode were prepared under optimal condition. The electrode chosen for surface modification is paraffin wax impregnated graphite electrode (PIGE) (Length- 150 mm, Diameter$3 \mathrm{~mm}$ ). Poly curucmin film (PCR) modified electrode was prepared by electropolymerization using cyclic voltammetry technique. Briefly bare PIGE was dipped in curcumin solution $(25 \mathrm{mM})$ in $0.1 \mathrm{M}$ phosphate buffer, pH-7.08 and a cyclic sweep potential was carried out for 20 cycles at the potential range form -0.3 to $0.8 \mathrm{~V}$ using cyclic voltammetry technique. For preconcentration of metal ions, the PCR electrode was dipped in metal ion solutions and a respective metal reduction potential was applied for individual metal ions via chronoamperometric technique. These electrodes were then taken for ED-XRF

\section{Results and Discussion}

The X-ray spectra of the electrodes are shown in figure 1. Measurement of $\mathrm{Pb}, \mathrm{Zn}$ and $\mathrm{Hg}$ content at the PCR modified electrode were carried out using EDXRF. The spectra shows L X-ray peak for different metals at its corresponding energies. Figure 1(a) showed the spectrum acquired from the Pb preconcentrated PCR modified electrode, where X-ray ( $L \alpha$ and $L \beta$ ) was seen with increased high count. Both the line group of $\mathrm{Pb}$ showed increased proportion only at $\mathrm{Pb}$ preconcentrated PCR modified electrode. Similar observation was recorded in the Hg preconcentrated PCR electrode where Hg exhibited different line group ( $\mathrm{L} \alpha$ and $\mathrm{L} \beta$ ) with increased $\mathrm{L} X$ ray peak count is depicted in fig. $1(\mathrm{c})$. A large intense peak area was observed for the X-ray $\mathrm{K} \alpha$ line group for $\mathrm{Zn}$ and less intense $\mathrm{K} \beta$ line group for Zn were observed for X-ray spectrum of Hg preconcentrated PCR electrode illustrated in figure 1(b). Table 1 shows the counts of the metal ions.

\begin{tabular}{|c|c|c|c|c|c|c|c|}
\hline Sample & Ca & Fe & Co & Zn & Hg & Ga & Pb \\
\hline a & 523 & 281 & 1819 & 343 & - & 500 & 10800 \\
\hline b & 287 & 676 & - & 10102 & - & - & 506 \\
\hline c & 482 & 916 & - & 893 & 9586 & - & 1095 \\
\hline d & 523 & 281 & 1819 & 343 & - & 500 & 10800 \\
\hline
\end{tabular}

Table 1
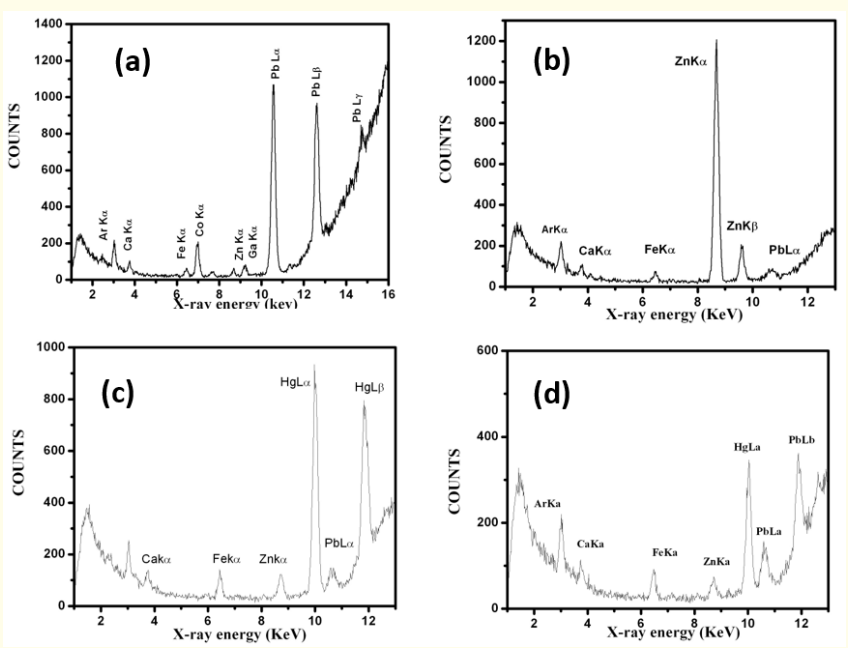

Figure 1: EDXRF spectra recorded for (a) Pb preconcentrated PCR modified electrode, (b) Zn preconcentrated at PCR modified electrode, (c) Hg preconcentrated at PCR modified electrode, (d) for simultaneous determination of all three metal ion preconcentrated at PCR modified electrode.

Two-crystal EDXRF recorded for elemental content at the surface of (a) Pb preconcentrated PCR modified electrode, (b) Zn preconcentrated at PCR modified electrode, (c) Hg preconcentrated at PCR modified electrode, (d) for simultaneous determination of all three metal ion preconcentrated at PCR modified electrode

\section{Conclusion}

Mercury and Lead have close K X-ray peak energy and same effect simultaneous determination of all three metal were carried out by preconcentrating all three metals at the PCR modified electrode. The line group of Mercury and Lead showed increased count where as that of Zinc showed lesser count. X-ray energy values of all metals were recorded in table 1 . From the above inference we conclude that the PCR modified electrode favored effective chelation for lead and mercury.

\section{Bibliography}

1. K Krishna., et al. "Polycurcumin nanospheres modified electrode for nanoscale detection of mercury ions in seawater". Chemical Physics Letters 781 (2021). 
2. Mahdiyeh Yaghooti., et al. "The role of curcumin and its derivatives in sensory applications". Materials Science and Engineering: C 103 (2019): 109792.

\section{Assets from publication with us}

- Prompt Acknowledgement after receiving the article

- Thorough Double blinded peer review

- Rapid Publication

- Issue of Publication Certificate

- High visibility of your Published work

Website: www.actascientific.com/

Submit Article: www.actascientific.com/submission.php

Email us: editor@actascientific.com

Contact us: +919182824667 